\title{
The role of infection in irritable bowel syndrome
}

\author{
Hani Abu Zeid* Magdi Abdel Karim* Mahmoud M. Bazid* \\ Mostafa M. Al Sayed* and Mostafa Yousef El-Mishad**
}

\author{
Internal Medicine Department $* \&$ Microbiology and Clinical \\ Immunology Department ** - Al Azhar University - Cairo.
}

\begin{abstract}
A clinically distinct subset of Irritable Bowel syndrome (IBS) could be induced or exaggerated by bowel infection that is called post-infective IBS (PI-IBS) which is characterized by diarrhea predominant symptoms with less psychiatric illness. The purpose of this work was to study whether some bowel infections contribute to the pathogenesis of IBS and whether the treatment of such infections reduces IBS symptoms.

100 patients with symptoms suggestive of IBS according to Rome II Criteria were chosen from Internal Medicine outpatient clinic-Al Hussein university hospital. They were 64 females and 36 males, aged 18-52 years old with mean age 38,2 $\pm 3,6$ years. They were submitted to: full clinical examination and frequent stool examinations (direct smear and culture) before, soon after and six months after administration of drug therapies for common stool-positive associated bowel infections (diloxanide for E. histolytica, metronidazole for Giardia lamblia, Ketoconazole for Candida, ciprofloxacin for Salmonella and neomycin for Pseudomonas).

Results obtained showed that $24 \%$ of patients had diarrhea predominant symptoms, 13 patients (54\%) out of them had history suggestive of acute gastroenteritis.

80 patients had initial positive stool examination and continued the post treatment six months follow up study. Out of them, 13 patients had stool positive for Salmonella typhi mixed with E. histolytica; ten of them (76.9\%) showed a statistically significant persistent clinical and laboratory improvement after ciprofloxacin therapy $(\mathrm{P}<0.01)$. So Salmonella typhi may be implicated in IBS pathogenesis.
\end{abstract}

Six patients showed isolated Giardia lamblia infection; four of them $(66.7 \%)$ showed a statistically significant persistent clinical and laboratory improvement after metronidazole thereby $(\mathrm{P}<0.05)$. Giardia lamblia parasite may be considered in triggering or exaggerating IBS symptoms.

24 patients had isolated E. histolytica infection; only one of them (4.2\%) showed sustained clinical and Laboratory improvement after diloxanide therapy -statistically insignificant result$(\mathrm{P}>0.05)$. This finding makes the correlation between E. histolytica infection and IBS is unlikely.

20 patients had isolated Candida overgrowth on stool examination; eight of them (40\%) showed a statistically significant clinical and laboratory improvement after Ketoconazole therapy $(\mathrm{P}<0.05)$. Therefore Candida overgrowth may induce or exaggerate IBS symptoms.

Finally, no growth was noticed for shigella sp. or E. coli, this may exclude the role of such organisms in IBS pathogenesis.

\section{Introduction and Aim of the Work:}

Irritable bowel syndrome (IBS) is a group of symptoms of multidetermined pathogenesis. Its symptoms seem to be generated by gut abnormalities in motility, epithelial function and sensory perception (Tornblom et al., 2003). These symptoms include abdominal pain, cramps, bloating and eccentric bowel movement ranging

from diarrhea to constipation. Symptoms are variable in intensity from one patient to another and from one time to another in the same patient. (Neal, et al., 2002). IBS represents $30-40 \%$ of GIT outpatient visits. It is prevalent among middle age individuals particularly females (Mark et al., 2000). 


\section{The role of infection in irritable bowel syndrome}

Nowadays there is an emerging evidence for the role of infection in the pathogenesis of IBS. A clinically distinct subset of IBS is caused by enteric infection that is called post-infectious irritable bowel syndrome (PI-IBS). It is characterized by diarrhea predominant symptoms, less psychiatric illness and increased seretonincontaining enteroendocrine cells (EC) compared to those with non post infective IBS (Simon et al., 2003). Clinically, their manifestations include abdominal pain, bloating, functional diarrhea, expulsing stools, urgency and even stool incontinence (Laurine, 2003).

The purpose of this work was to study whether bowel infections play a role in the pathogenesis of IBS and whether the treatment of such infection reduces IBSsymptom.

\section{Patients and Methods:}

The study was carried out on 100 patients with symptoms suggestive of IBS according to Rome II criteria. They were selected from Internal Medicine out patient clinic at Al Hussien University hospital (from Oct. 2003 to May 2004). They were 36 males and 64 females, aged 18-52 years with mean age $38.2 \pm 3.6$ years. Patients fulfilled symptoms essential for diagnosis of IBS, reported by Thompson et al. (1999) according to Rome II criteria: at least three months of continuous or recurrent abdominal pain or discomfort that has at least two out of three features: (1) relieved with defecation and/or. (2) Onset associated with frequency of stool and/or. (3) Onset associated with a change in the consistency of stool, in addition to other supportive but not essential symptoms such as bloating and passage of mucus.

All patients were subjected to the following:-

* Full history taking: including diet habits, change in bowel habits, bloating, abdominal pain and its relation to defecation; whether these symptoms followed an attack of acute gastrointestinal infection. History of psychiatric troubles was also taken.
* Thorough clinical examination: for palpable or tender colon, gaseous distension and intestinal sounds (exaggerated peristalsis).

* Stool examination: stool were collected from patients in clean cups to be investigated for the presence of microorganisms that may be contributed in IBS pathogenesis; using the following; according to Collee et al, 1997 \& Collin et al., 2001:

a - Direct smear examination: saline iodine dissolved stool samples were examined by ordinary microscopy for the presence of Entameba histolytica, Giardia lamblia parasites and Candida overgrowth.

b - Culture of Stools: stools were inoculated on selenite broth medium, incubated at $37^{\circ} \mathrm{C}$ for 18 hours, then inoculated on MacConky's agar and DCA agar plates which were reincubated at $37 \mathrm{C}$ for 24 hours.

Any growth on plates was studied for colonial morphology then gram stained films from colonies were prepared to study morphology of the cultivated organisms and its biochemical reactions.

* Courses of specific treatment: were given for patients with stools positive for various gut microorganisms as follow:

- Diloxanide $500 \mathrm{mg}$ three times a day for 10 days for E. histolytica, (Carlos et al., 2001).

- Metronidazole $2000 \mathrm{mg}$ once a day for 3 successive days for Giardia lamblia (Carlos et al., 2001).

- Ketoconazole $200 \mathrm{mg}$ once a day for ten days (Shubhada et al., 2001).

- Ciprofloxacin $500 \mathrm{mg}$ twice a day for 21 days for salmonella typhi, paratyphi A \& B. (Carlos et al., 2001).

* Post treatment clinical evaluation and stool examination were carried out, soon after termination of specific antimicrobial courses and after six months for only 80 patients out of 100 studied patients with IBS (eight patients had 
free stools and 12 patients discontinued the study).

* Statistical Methods: obtained data were analyzed by computer using (a) mean value (b) standard deviation $\mathrm{SD} \pm$ (c) Chi-square test: to test for significant relation between qualitative variables or percentages.

- Significant values were considered at : $\mathrm{P}<0.05$

\section{Results:}

Results obtained were analyzed, tabulated and illustrated in: tables (1-4)

Table (1): Groups of Studied IBS patients in relation to bowel habit symptoms.

\begin{tabular}{|l|l|l|}
\hline \multirow{2}{*}{ Group } & \multicolumn{2}{|l|}{ IBS patients : No. $=100$} \\
\cline { 2 - 3 } & No. & $\%$ \\
\hline Constipation predominant patients & 33 & $33 \%$ \\
\hline Diarrhea predominant patients & 24 & $24 \%$ \\
\hline Alternating constipation \& diarrhea patients & 43 & $43 \%$ \\
\hline
\end{tabular}

Table (2): Prevalence of patients with history suggestive of acute gastroenteritis prior to occurrence of IBS symptoms and their mood state.

\begin{tabular}{|c|c|c|c|c|}
\hline & \multicolumn{4}{|c|}{ IBS patients: No. $=100$} \\
\hline \multirow{3}{*}{$\begin{array}{l}\text { History suggestive } \\
\text { of acute gastroenteritis }\end{array}$} & \multicolumn{2}{|c|}{ +ve history patients } & \multicolumn{2}{|c|}{-ve history patients } \\
\hline & No. & $\%$ & No. & $\%$ \\
\hline & 13 & $13 \%$ & 87 & $87 \%$ \\
\hline Mood state & $\begin{array}{l}\text {-averas } \\
\text { patient } \\
\text {-anxiet }\end{array}$ & $\begin{array}{ll}\text { d: } & 12 \\
\text { ient } & \end{array}$ & $\begin{array}{l}\text {-averag } \\
\text { patient } \\
\text { - anxie } \\
\text { - depre }\end{array}$ & $\begin{array}{l}\quad 48 \\
\text { ats } \\
\text { tients }\end{array}$ \\
\hline
\end{tabular}

Table (3): Initial laboratory findings of stool examination:

\begin{tabular}{|l|l|l|}
\hline \multirow{2}{*}{$\begin{array}{l}\text { Stool examination } \\
\text { (direct smear \& culture) }\end{array}$} & \multicolumn{2}{|l|}{ IBS patients No.=100 } \\
\cline { 2 - 3 } A) Negative: & 8 & $\%$ \\
\hline B) Positive: & 92 & $8 \%$ \\
\hline (i) Single infection & & $92 \%$ \\
\hline - E. histolytica. & 25 & $27.1 \%$ \\
\hline - Giardia Lamblia. & 6 & $6.5 \%$ \\
\hline - Candida. & 28 & $30.4 \%$ \\
\hline (ii) Double infection & & \\
\hline - E. histolytica, \& pseudomonas. & 1 & $1.1 \%$ \\
\hline - E. histolytica, \& S. typhi. & 14 & $15.2 \%$ \\
\hline - E. histolytica, \& candida. & 4 & $4.3 \%$ \\
\hline - E. histolytica, \& S. paratyphi - A. & 1 & $1.1 \%$ \\
\hline - E. histolytica, \& S. paratyphi -B. & 3 & $3.2 \%$ \\
\hline - Candida \& pseudomonas. & 1 & $1.1 \%$ \\
\hline - Candida \& S. typhi. & 6 & $6.5 \%$ \\
\hline - Candida \& S. paratyphi -A. & 1 & $1.1 \%$ \\
\hline (iii) Triple infection & & \\
\hline -E. histolytica, Candida \& pseudomonas & 2 & $2.1 \%$ \\
\hline
\end{tabular}


Table (4):Percentages of post-treatment improvement (both clinical \& laboratory) in relation to the type of bowel infection among 80 patients with positive stool examination who continued the six months-follow up study.

\begin{tabular}{|l|l|l|l|l|l|}
\hline & Gut infection & $\begin{array}{l}\text { Total No. } \\
\text { of patients }\end{array}$ & $\begin{array}{l}\text { No. of } \\
\text { patients } \\
\text { improved }\end{array}$ & $\%$ & P-value \\
\hline Singl infection & - E. histolytica, & 24 & 1 & $4.2 \%$ & $>0.05$ \\
\hline & - Giardia L. & 6 & 4 & $66.7 \%$ & $<0.05$ \\
\hline & - Candida & 20 & 8 & $40 \%$ & $<0.05$ \\
\hline Double infection & - E. histolytica+ pseud. & 1 & 1 & $100 \%$ & $<0.001$ \\
\hline & - E. histolytica, +S.typhi & 13 & 10 & $76.9 \%$ & $<0.01$ \\
\hline & - E. histolytica, +Candida & 3 & 0 & $0.0 \%$ & $>0.05$ \\
\hline & -E.histolytica,+S.paratyphi.A & 1 & 1 & $100 \%$ & $<0.001$ \\
\hline & -E.histolytica,+S.paratyphi-B & 3 & 2 & $66.7 \%$ & $<0.05$ \\
\hline & - Candida + S typhi & 6 & 6 & $100 \%$ & $<0.001$ \\
\hline & Candida+S.Paratyphi-A & 1 & 1 & $100 \%$ & $<0.001$ \\
\hline Triple infection & $\begin{array}{l}\text { - E. histolytica +Candida }+ \\
\text { pseudomonas. }\end{array}$ & 2 & 0 & $0.0 \%$ & $>0.05$ \\
\hline Total & & 80 & 34 & $42.5 \%$ & X2:13.95 \\
\hline
\end{tabular}

\section{Discussion:}

Irritable bowel syndrome (IBS) is one of the common gastrointestinal diseases, usually involve middle age population, predominantly females. It is characterized by abdominal pain, cramps and eccentric bowel movement ranging from diarrhea to constipation (Neal; 2002).

A clinically distinct subset of IBS is induced by gut infections that is called postinfective IBS (PI-IBS) which is characterized by diarrhea predominant symptoms with less psychiatric illness (Simon et al., 2003). This goes with results obtained from this study that diarrhea predominant IBS patients were $24 \%$ (table 1). 13 patients (54\%) out of them had history suggestive of acute gastroenteritis prior to IBS symptoms without clear history of psychiatric illness (Table 2).

In this study, out of 80 stool positive patients who continued the study, 13 patients showed mixed salmonella typhi and E. histolytica infection; ten patients out of them (76.9\%) showed a statistically significant clinical and laboratory improvement after Ciprofloxacin therapy ( $\mathrm{P}<$ 0.01) (table 4). Since patients with isolated E. histolytica infection showed a statistically insignificant clinical and laboratory improvement (4.2\%), after diloxanide therapy $(\mathrm{P}>0.05)$ (table 4$)$, salmonella typhi infection could be considered in IBS pathogenesis. This goes with the reports of Jonathan et al., 2001 that IBS symptoms may develop in patients after acute salmonella infection.

Six patients out of the 80 stool positive patients had isolated Giardia Lamblia infection, four patients out of them (66.7\%) showed a statistically significant sustained clinical and laboratory improvement after metronidazole therapy $(\mathrm{P}<0.05)$ (table 4). This finding is consistent with what was published by Rose, 2002 that concurrent Giardia lamblia infection induced exaggerated IBS symptoms in patients with prior IBS, so Giardia lamblia becomes clinically evident by eliciting symptoms of established IBS.

On the other hand; 24 patients out of the 80 stool positive patients showed isolated E. histolytica infection on direct smear examination, only one of them (4.2\%) showed sustained clinical and laboratory improvement after Diloxanide therapy -a statistically insignificant result$(P>0.05)$ (table 4), therefore E. histolytica infection is unlikely to be implicated in IBS pathogenesis. This finding goes with what was reported by Sinha et al., 2003, that bowel symptoms in IBS with concurrent E. histolytica infection were not related to the parasite in their study. Controversially, this finding doesn't go with what was published 
by Madanagopalan et al., (1996) that chronic intestinal amebiasis can present in many forms, one of them is characterized by IBS-like symptoms.

20 patients out of the 80 stool positive patients showed candida overgrowth, eight of them (40\%) showed a statistically significant sustained clinical and laboratory improvement after Ketoconazole therapy $(\mathrm{P}<0.05)$ (table 4). This finding goes with what was published by William, 2003 that intestinal Candidiasis could be associated with allergic reaction to food and symptoms consistent with IBS symptoms including bloating, cramping gut pain, gurgling in the bowel and diarrhea.

No growth for shigella sp. or E. coli was noticed on initial stool culture for all IBS studied patients. This may make the role of shigella sp. \& E. coli in the pathogenesis of IBS is unlikely. Although this finding is controversial to what was reported by Jonathan et al., (2001) that IBS symptoms may develop in patients following acute infection with such organisms.

\section{Recommendation}

** IBS patients should undergo frequent stool examination to rule out associated bowel infections which may contribute in induction or exaggeration of IBS symptoms. Treatment of such infections may reduce these symptoms.

** Large scale studies on IBS patients are recommended for further and precise finding out the role of different gut infections; including Campylobocter infection (which needs a special protocol of stool examination for its diagnosis) in IBS pathogenesis.

\section{References}

1. Carles M, Barnard L, hortanp. And Larry D (2001): Infectious diseases hand book $4^{\text {th }}$ ed

2. Collee N, G. A , Bouck DA, 1997: Oragnostic medical microbiology $3^{\text {rd }}$ ed, Washington Dc; ASM: 14-17.

3. Collin SM; Bish T and Rambal B, 2001: The putative role of inflammation in IBS. Gut, 49: $743-745$.
4. Jonathan P. Thornley, David Jenkins, keith neal, trina wright, Jo Brough, and Robin CSpiller, 2001: Relationship of compylabacter toxigenicity in vitro to the post-infective Irritable Bowel Syndrome. Infectious Diseases; 184 : 606 - 9 .

5. Laurine B. 2003: Infectious gastroenteritis linked to irritable bowel Syndrome. J. Med. Virol.; 71 : $56-61$.

6. Madanagopalan N., Vedachalan SB., and Subramaniam R., 1996: Rectal and colonic mucosal biopsy and faeces correlation in Amebiasis and other colitis. Gut; 9: 106.

7. Mark, Evelyn J. Chow, B A and Henry C. and lin MO, 2000: Eradication of small intestinal bacterial over-growth reduces symptoms of Irritable Bowel Syndrome. The American Journal of Gostroenterology, vol. 95; No 12.

8. Neal K., Barker L, and Spiller R; 2002: Prognosis in post-infective Irritable Bowel Syndrome: A six year follow up study. Gut; 51: 410- 413.

9. Shubhada $\mathbf{N}$, Kelli $\mathbf{F}$ and Subramanian $\mathbf{P}$ (2001) : The Washington manual of medicl Therapeulics. $30^{\text {th }}$ ed P: 320.

10. Simon P. Dunlap, M., Davids M, Robin C. and spiller, R., 2003: Distinctive clinical, psychological and histological features of postinfective trritable Bowel syndrome. The American Journal of Gastroenterlogy; vol. 98: 1578 - 1583.

11. Sinha P, Ghoshal UC, Choudhuri G, and Naik SR, 2003: Does Entamoeba Histoloytica cause irritable bowel syndrome?. Scand. J. infect. Dis 35: 186 - 188.

12. Thompson, W.; Longstreth G.; D.A., et al., 1999: Functional bowel disorders and functional abdominal pain. Gut; 45 (Suppl 2): 1143-1147.

13. Tornblom H., Lindbergs G, and Nyberg B, 2003: Histopathological finding in the jejunum of patients with irritable bowel syndrome. Gastroenteralogy; 118 (Suppl 1); A 140.

14. Rose, 2002: Irritable Bowel syndrome affects large number of patients with symptomatic Giardiasis: "Giardia Lamblia infection became clinically evident by eliciting symptoms of Irritable Bowel Syndrome". Journal of infection; 45 (3): $163-177$.

15. William G. Crook; 2003: Candida presentation; Clinical Infectious Dis; 26 (3): $556-59$. 


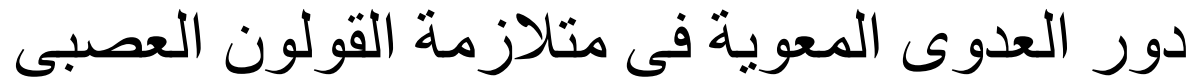

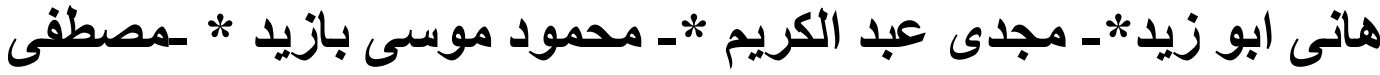

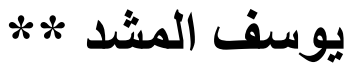 \\ اقسام الامراض الباطنة العامة و ** المئن الميكروبيولوجى والمناعة

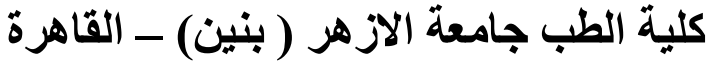

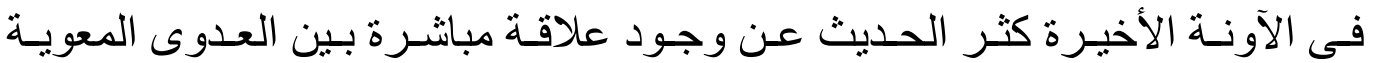

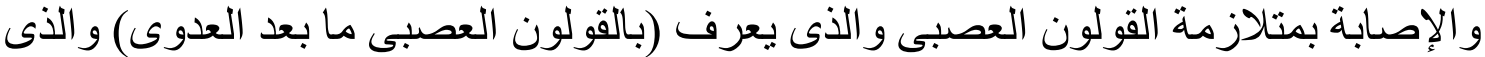

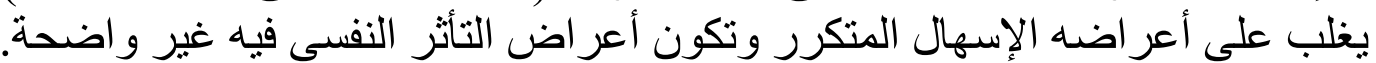

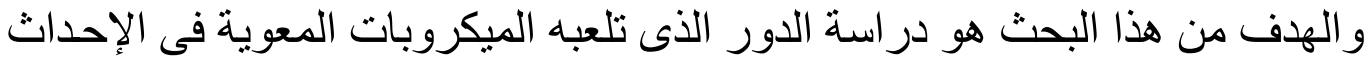

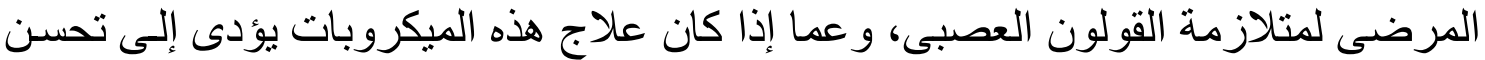

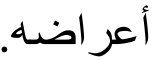
لهذا الهدف تم اختيار مائة مريض بمتلازمة القولون العصبى (حسب تصنيف روماً -

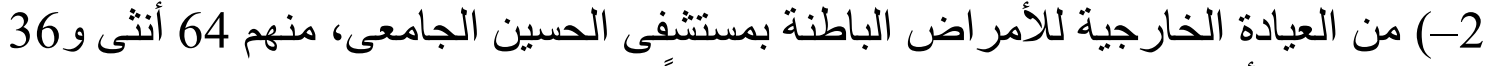

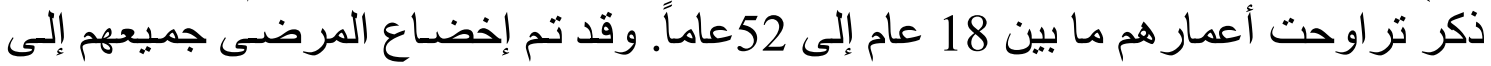

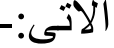

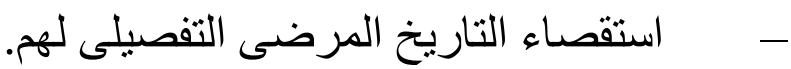

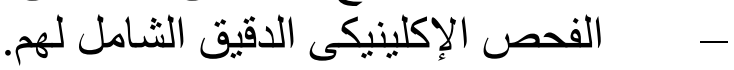

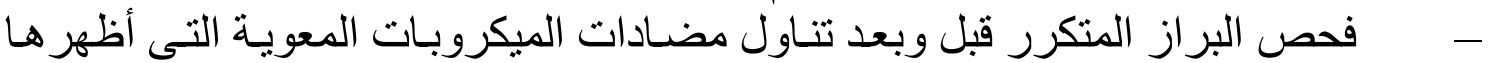

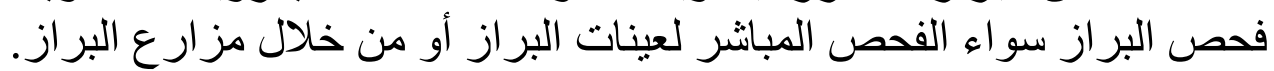

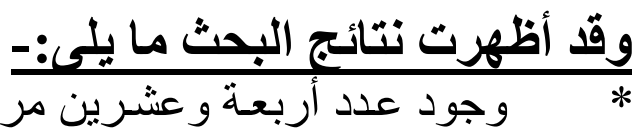

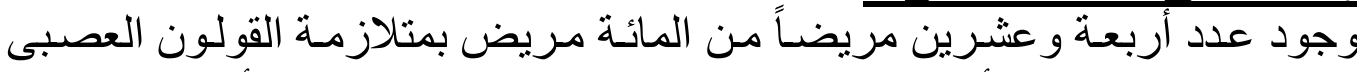

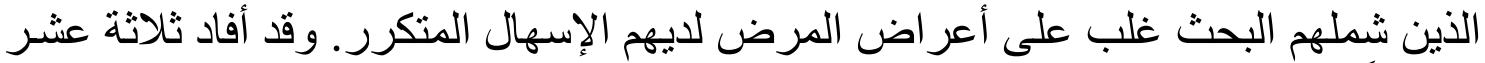

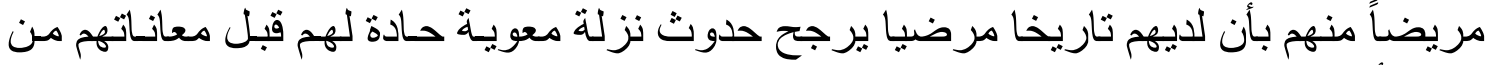

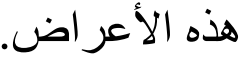

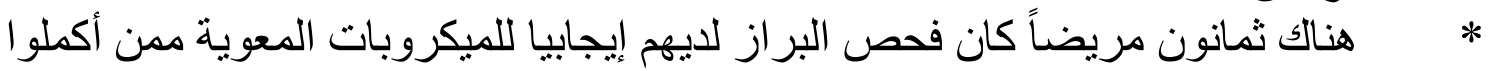
متابعة الدر اسة الى نهايتها.

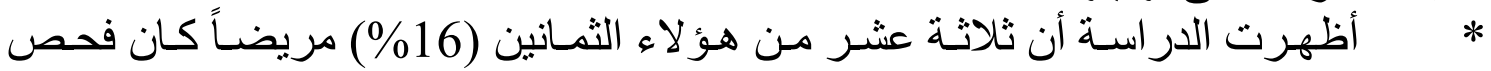

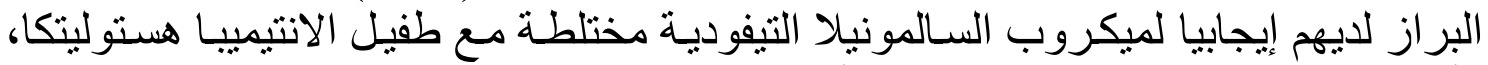

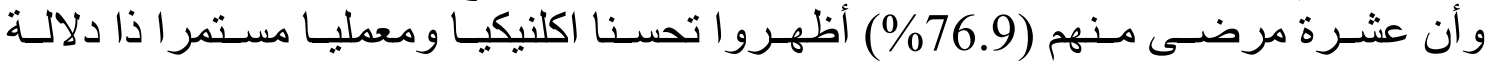

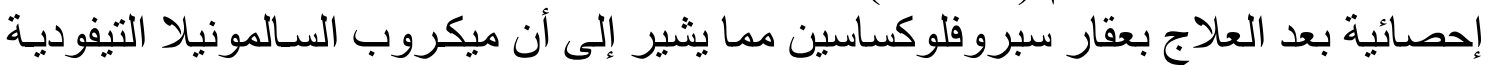

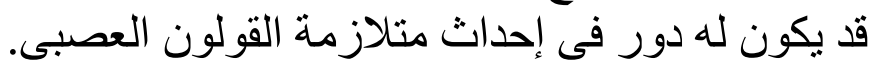

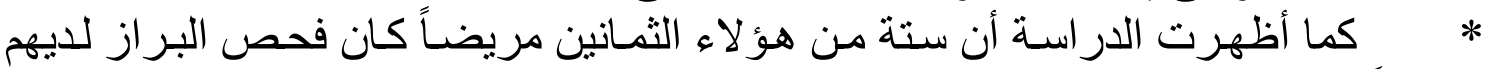

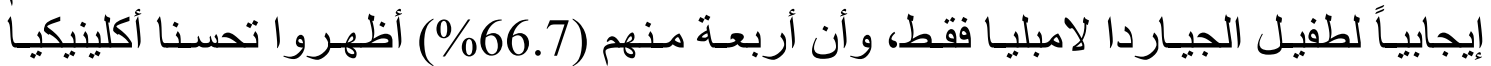

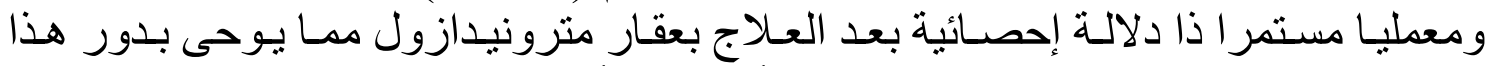
الطفيل فى إحداث متلازمة القولون العصبى أو إظهار أعر اضهد وزيادة حدنها. 


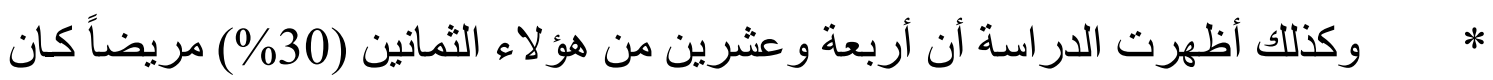

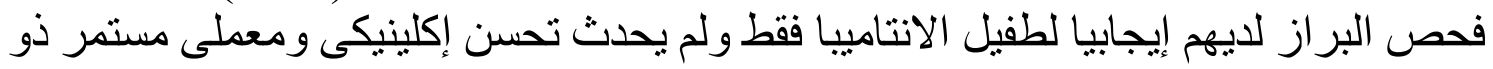

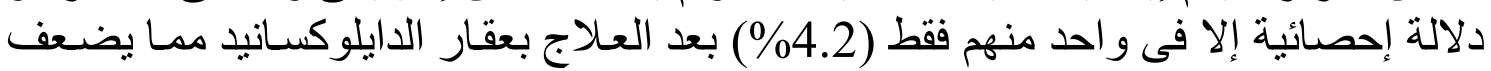

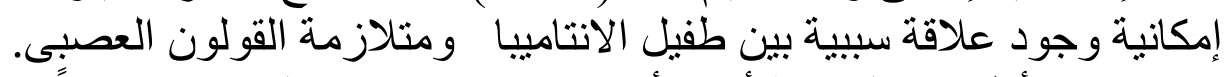

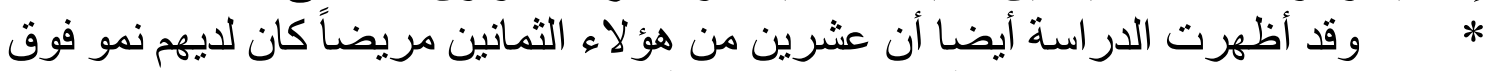

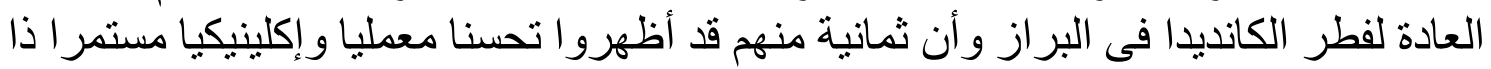

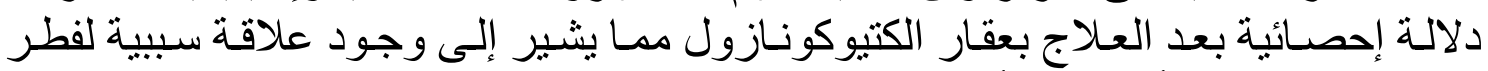

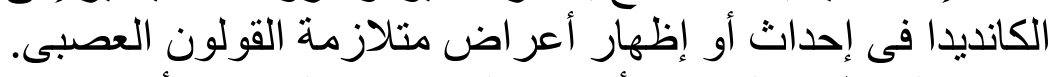

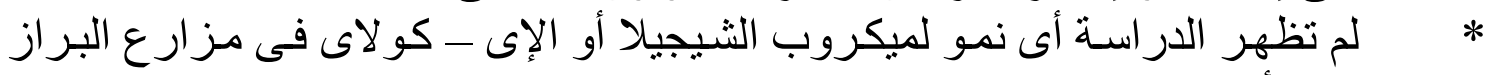

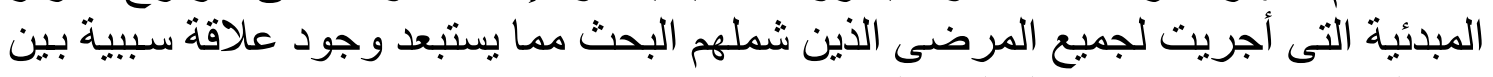

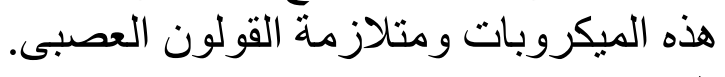

التوصيات :

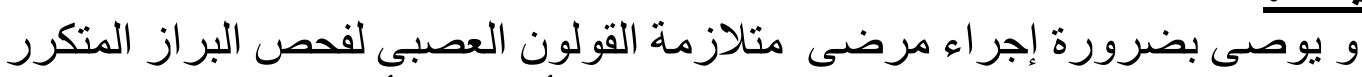

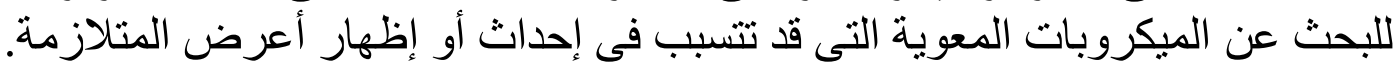

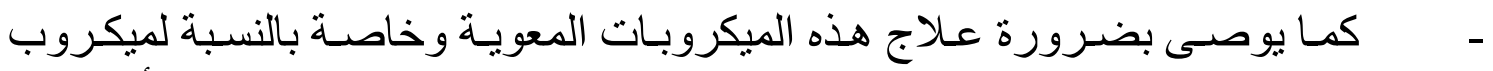

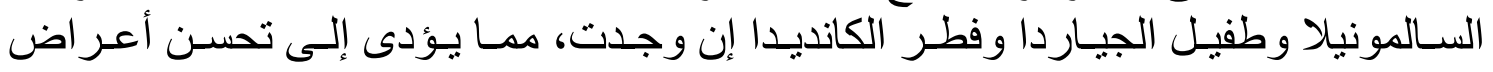

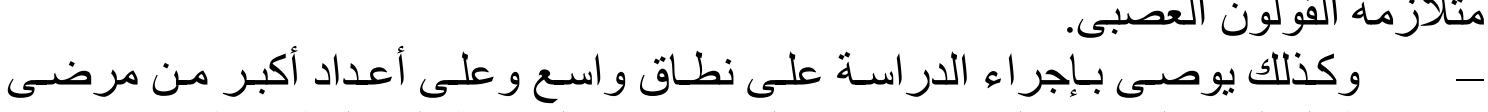

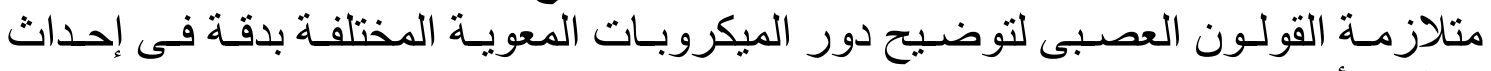

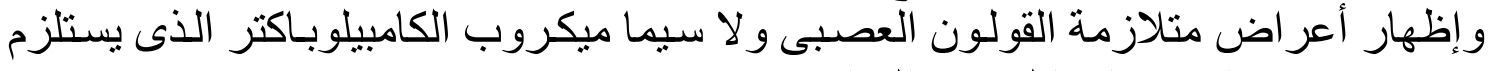
تشخيصه بروتوكو لا خاصـا لفحص البرون البراز 